\title{
Participant Characteristics That Influence Consent for Genetic Research in a Population-Based Survey: The Baltimore Epidemiologic Catchment Area Follow-Up
}

\author{
Briana Mezuk William W. Eaton Peter Zandi \\ Department of Mental Health, Johns Hopkins Bloomberg School of Public Health, Baltimore, Md., USA
}

\section{Key Words}

Genetic research · Blood donation - DNA storage

\begin{abstract}
Background: The purpose of this study is to investigate the sociodemographic and health characteristics associated with the willingness to donate a DNA sample, and consent to testing and long-term storage of that sample, among participants in a longitudinal community-based survey. Sample: Eighty-three percent of the 1,071 participants interviewed in 2004/5 agreed to donate a biological specimen (blood or buccal). Results: Age was consistently inversely associated with the willingness to allow genetic testing (OR $0.97 ; p<0.05)$, but was unrelated to the willingness to donate or allow storage. There was no association between race and the consent to donate a specimen, but Blacks were less likely to consent to DNA storage for future research as compared with members of other racial groups (OR 0.50; $p<0.01$ ). Four conditions were listed on the consent form as relevant to the genes targeted for assay. Participants with a family history of 1 or more of these conditions were more likely to donate than those without (OR 1.68; $p<0.01$ ). Participants with a personal history of 1 of the 4 conditions listed were not more or less likely to donate, allow testing or allow storage than respondents without such a history. Conclusions: Sociodemographic characteristics were unrelated to the willingness to donate a biological sample. Age, but not race, sex or edu-
\end{abstract}

cation, was related to consent to genetic testing. Race, but not age, sex or education, was related to consent to storage. A family history of health conditions listed as relevant to the assays being requested was related to the willingness to donate. Factors that affect the willingness to donate a biological sample in an epidemiologic study are not the same as those associated with the willingness to allow genetic testing or storage of that sample for unspecified future research.

Copyright $\odot 2008$ S. Karger AG, Basel

\section{Introduction}

Collection of biological and genetic information is associated with unique procedures and respondent burdens that go beyond traditional observational epidemiologic research. Some participants are reluctant to donate a biological specimen due to concerns about disclosure of genetic information, and as a result, the collection of biological specimens is often less complete than the collection of other survey data. Gathering genetic samples in population-based epidemiologic research is crucial to studying gene-environment interactions, particularly between common environmental exposures and lowpenetrance alleles [1]. Most studies examining the acceptability of genetic research have relied on clinic samples or subpopulations defined by risk status $[2,3]$. There

\section{KARGER \\ Fax +4161306 1234 \\ E-Mail karger@karger.ch}

www.karger.com
(C) 2008 S. Karger AG, Basel

$1422-2795 / 08 / 0113-0171 \$ 24.50 / 0$

Accessible online at:

www.karger.com/cmg
Briana Mezuk

624 North Broadway

Suite 886

Baltimore, MD 21205 (USA)

Tel. +1 443287 8630, Fax +1 410955 9088, E-Mail bmezuk@jhsph.edu 
is little empirical research examining the characteristics associated with the willingness to participate in genetic components of observational population-based studies; research concerning the acceptability of genetic studies has tended to rely on participants' responses to hypothetical research situations [4-7]. Recently, the National Health and Nutrition Examination Survey reported a trend for non-Hispanic Black survey participants to be less willing to donate a DNA sample for future research compared with other racial groups [8], whereas smaller community-based samples have reported no association between race and the donation of DNA [9]. Additionally, there have been conflicting reports regarding the influence a family history of disease has on the willingness to participate in research $[10,11]$. Disparities such as these threaten the internal validity of the study findings, specifically concerning selection bias and population stratification. Selection bias occurs when the relationship between an exposure (e.g., genotype) and outcome (e.g., phenotype) is different for those who actually participate compared with those eligible for the study [12]. Selection bias can lead to spurious associations between exposures and outcomes $[13,14]$. Population-stratification of exposures (e.g., candidate alleles) and outcomes can lead to spurious associations between genotype and phenotype that have no causal significance [15]. If certain groups (e.g., ethnic groups) are more or less willing to participate in population genetic research, associations found between an allele and a phenotype may be due only to different allele frequencies between groups within the study sample rather than having any causal significance [16].

There are 3 primary methods for obtaining a DNA sample in a large epidemiologic survey: blood (both venous blood and blood spots), cheek (buccal) swab and mouthwash. These methods have been used to different degrees of success, both in terms of subject participation and DNA yield [17-19]. Because of the quick pace of genetic research, there has been a push recently to ask subjects to consent to storage of their DNA sample for as-yet undetermined future analyses [1], and there are several such 'bio-banks' currently operating worldwide (e.g., UK Biobank) [20]. This approach may have various levels of acceptability among different subpopulations, even if they are willing to donate DNA for specific analyses described in the consent form $[5,8,21]$.

The purpose of this study was to investigate the sociodemographic, mental and physical health characteristics associated with the willingness to donate a DNA sample and consent to long-term storage of that sample in a longitudinal community-based survey, the Baltimore Epidemiologic Catchment Area (ECA) Study. Results from this study may inform the design and execution of future molecular epidemiologic population-based studies.

\section{Method}

\section{Sample}

The Baltimore site of the ECA Study was 1 of 5 sites of the National Institute of Mental Health ECA Project, which was initiated in 1981 to document the prevalence, incidence and natural history of psychiatric disorders in the general population [22]. The Baltimore site has conducted 4 survey waves over the past 23 years. In the wave $42004 / 5$ follow-up, self-report survey data were collected on 1,071 members of the original 3,481 respondents. The wave 4 sample included 63\% females, 62\% Caucasians, 35\% African-Americans and 3\% other racial groups, which is nearly identical to the composition of the original cohort. All cohort members were at least 18 years old in 1981, and thus, all respondents were at least 40 years old at the 2004/5 follow-up. In addition to the questionnaire, all 2004/5 follow-up participants were asked to donate a biological sample. The 1,071 participants interviewed at wave 4 were the focus of this study.

\section{Collection of Biological Samples}

Participants were initially asked to donate a blood sample, and if they were unwilling and/or unable to donate, they were asked to donate a buccal (cheek) sample instead. Participants received a honorarium of USD 125 for participating in the survey, but did not receive any additional compensation for agreeing to donate a biological sample or consenting to genetic testing storage of that sample.

There were 3 separate consent forms used in the survey: (1) a study questionnaire, (2) collection of a blood sample, and (3) collection of a buccal sample. Some participants were interviewed by phlebotomist interviewers who would discuss the biological collection procedures and draw blood from consenting participants immediately following the questionnaire, while others were interviewed by non-phlebotomist interviewers who would discuss the biological sample collection portion of the study and confirm that a study phlebotomist could contact the participant about the procedure. The willingness to donate a biological sample was determined by whether or not the participant signed either the blood or buccal consent form.

Both the blood and buccal collection consent forms contained 2 options concerning the genetic analysis of the sample indicated by individual check boxes: (1) consent to only specified genetic analyses, and/or (2) storage of the DNA sample for unspecified future research. The 4 genetic analyses specified in the consent form were apolipoprotein $\varepsilon$ (APOE), serotonin transporter (5HTT), monoamine oxidase A (MAOA) and tyrosine hydroxylase $(\mathrm{TH})$. The respondents indicated whether they would allow analysis of the specified genes, storage of their DNA sample for future genetic analysis, neither, or both, an approach recommended for population-based research [1]. Consent to allow specified genetic testing was determined by whether or not the participant had checked the box stating: 'I agree to the following: 
testing APOE, 5HTT, TH and MAOA.' Consent to allow storage of DNA for unspecified future research was determined by whether or not the participant had checked the box stating: 'I agree to the following: storage of my DNA for other medical research.' Concerning the 4 specified genes, the consent form stated: 'These genes are associated with dementia, diabetes, depression, and cardiovascular disease.' Concerning the need to store the participant's DNA sample indefinitely for future unspecified analyses, the consent form stated: 'Your DNA may be use to study the genetic influences of genes other than the ones listed above on the health and mental health problems of people like you. Since important genes no one knew about are being identified all the time, and will be in the future, it will help the success of the study if you allow us to grow a cell line and study genes that have not yet been identified.'

\section{Measurement of Physical and Mental Health Characteristics}

Diagnosis of major depressive disorder was determined using the Diagnostic Interview Schedule, a self-report instrument designed for the ECA Project that contains items and probes intended to replicate a psychiatrist's interview [23]. The validity and reliability of the Diagnostic Interview Schedule has been investigated in the ECA sample with conservative results (e.g., it tends to under- rather than overdiagnosis relative to a psychiatrist's interview) for nonpsychotic conditions (e.g., depression and anxiety) [24]. The participant's physical health conditions ('Have you ever had...') and family history of health conditions ('Did your mother, father, sisters or brothers have...') were assessed by selfreport. Self-report measures of diabetes [25], angina [25], heart surgery [25] and cancer [26] have been shown to be comparable with those assessed by medical records.

\section{Data Analysis}

All analyses were conducted using STATA (version 8) statistical software [27]. Multiple logistic regression was used to analyze 5 dichotomous outcomes: (1) consent to donate a blood sample, (2) consent to donate a buccal sample, (3) consent to donate a biological sample (blood and buccal combined), (4) consent to genetic testing, and (5) consent to DNA storage for future research. Three sets of participant characteristics were investigated: sociodemographic variables (age, race, sex and years of education), family history of health conditions (the 4 conditions listed in the consent form described above and 2 common conditions - asthma and cancer - that were not listed for comparison), and participant physical and psychological health variables (again, the conditions listed in the consent form, with the exception of dementia, and 2 common conditions - asthma and cancer - that were not listed for comparison).

\section{Results}

\section{Demographic Characteristics}

Of the 1,071 participants interviewed, 683 agreed to donate a blood sample and 291 agreed to donate a buccal sample (some participants donated both due to incomplete blood draws). In total, 888 participants ( $83 \%$ of the sample interviewed at wave 4 ) agreed to donate a biolog- ical specimen in some form (table 1), and complete data were available on 885 of these participants. Ninety-seven percent $(n=861)$ of those who donated a biological sample agreed to genetic testing of the 4 loci listed in the consent form. Eighty-nine percent $(n=791)$ of those who consented agreed to storage of their DNA for future research.

Blacks were significantly less likely than members of other racial groups ( $94 \%$ of which were White) to consent to donate a blood sample (OR 0.618; 95\% CI 0.465-0.822). There was a nonsignificant trend for Blacks to be more willing to consent to donate a buccal sample in lieu of blood. As shown in table 2, there was no association between race and the consent to donate a biological sample (blood or buccal) in general (OR 0.93; 95\% CI 0.66-1.31) after adjusting for age, sex and education. There was no association between gender or age and the consent to donate a biological sample or allow genetic testing or storage of that sample. Blacks were half as likely to allow storage of their DNA sample for future research after controlling for age, sex and education as compared with members of other racial groups.

\section{Family History of Health Conditions}

The consent forms to donate blood and buccal samples specifically referenced 4 genes and 4 health conditions associated with those genes: dementia, diabetes, depression and cardiovascular disease (table 3). Participants with a family history of any of these 4 conditions were $68 \%$ more likely to consent to donate a specimen than those without a positive family history. However, a family history of these conditions did not affect the willingness to allow genetic testing or storage for future research. Participants with a family history of cardiovascular disease (including heart disease, stroke, heart surgery before age 60 and/or arteriosclerosis) were more likely to consent to donate a biological sample than those without, after adjusting for age, race, sex and education (OR 1.41; 95\% CI 1.02-1.96). However, there was no association with a family history of hypertension or high cholesterol and the willingness to donate (data not shown). This may be due to the fact that many participants are unaware of their family history regarding these conditions. There was no association with a family history of cardiovascular disease and the consent to DNA testing or storage. Participants with a family history of diabetes were more likely to consent to donate a biological sample (OR 1.82; 95\% CI 1.30-2.54) after adjusting for age, race, sex and education. Participants with a family history of depression were more willing to 
Table 1. Characteristics of the consent to donate a biological sample, allow genetic testing and allow storage for future research

\begin{tabular}{|c|c|c|c|c|c|}
\hline $\begin{array}{l}\text { Demographic } \\
\text { characteristics }\end{array}$ & $\begin{array}{l}\text { Consent to } \\
\text { blood sample }\end{array}$ & $\begin{array}{l}\text { Consent to } \\
\text { buccal sample }\end{array}$ & $\begin{array}{l}\text { Consent to } \\
\text { either/both }\end{array}$ & $\begin{array}{l}\text { Genetic } \\
\text { testing }\end{array}$ & $\begin{array}{l}\text { Genetic } \\
\text { storage }\end{array}$ \\
\hline \multicolumn{6}{|l|}{ Sex } \\
\hline Male & $250(63.0)$ & $106(26.7)$ & $328(82.6)$ & 318 [97.5] & 289 [88.7] \\
\hline Female & $443(65.7)$ & $185(27.4)$ & $560(83.1)$ & $543[97.1]$ & 502 [89.8] \\
\hline \multicolumn{6}{|l|}{ Race/ethnicity } \\
\hline White & $432(65.3)$ & $160(24.2)$ & $548(82.8)$ & $532[97.4]$ & 498 [91.2] \\
\hline Black & $225(60.2)$ & $121(32.4)$ & $307(82.1)$ & 297 [97.1] & 262 [85.6] \\
\hline Other & $26(74.3)$ & $10(28.6)$ & $33(94.3)$ & $82[97.0]$ & 31 [93.9] \\
\hline \multicolumn{6}{|l|}{ Age } \\
\hline $40-49$ years & $178(65.7)$ & $61(22.5)$ & $216(79.7)$ & 213 [98.6] & 196 [90.7] \\
\hline $50-59$ years & $240(59.7)$ & $122(30.3)$ & $332(82.6)$ & 321 [96.7] & 289 [87.0] \\
\hline $60-69$ years & $127(69.8)$ & $50(27.5)$ & $161(88.5)$ & 156 [96.9] & $145[90.1]$ \\
\hline $70-79$ years & $67(65.0)$ & $25(24.3)$ & $87(84.5)$ & 82 [94.3] & 79 [90.8] \\
\hline $80+$ years & $71(62.8)$ & $33(29.2)$ & $92(81.4)$ & 89 [96.7] & 82 [89.1] \\
\hline \multicolumn{6}{|l|}{ Education } \\
\hline$<12$ years & $194(66.4)$ & $71(24.3)$ & $241(82.5)$ & 234 [97.1] & 220 [91.3] \\
\hline$\geq 12$ years & $489(62.8)$ & $220(28.2)$ & $647(83.1)$ & 627 [97.4] & 571 [88.7] \\
\hline Total & 683 & 291 & $888^{\mathrm{a}}$ & $861^{\mathrm{b}}$ & 791 \\
\hline
\end{tabular}

Figures in parentheses indicate percentages of the total wave 4 sample $(n=1,071)$, and figures in brackets indicate percentages of the consent to donate either/both.

${ }^{a}$ This value is less than the sum of blood and buccal samples because some participants $(\mathrm{n}=85)$ provided consent for both blood and buccal samples due to incomplete blood draws.

$\mathrm{b}$ This value is less than the total number of people who consented to donate a specimen $(\mathrm{n}=888)$ because participants could choose to only allow nongenetic testing by not checking either of the boxes for specified genetic analyses or storage for future research.

Table 2. Demographic characteristics and relative odds of consent

\begin{tabular}{|c|c|c|c|}
\hline Demographic characteristics & $\begin{array}{l}\text { Donate biological } \\
\text { sample OR }{ }^{1}\end{array}$ & $\begin{array}{l}\text { Genetic testing } \\
\mathrm{OR}^{1}\end{array}$ & $\begin{array}{l}\text { Storage for future } \\
\text { research } \mathrm{OR}^{1}\end{array}$ \\
\hline Age, years & $1.00(0.99-1.02)$ & $0.97(0.94-1.00)^{*}$ & $0.99(0.97-1.01)$ \\
\hline \multicolumn{4}{|l|}{ Race } \\
\hline Black versus not-black & $0.93(0.66-1.31)$ & $0.73(0.30-1.78)$ & $0.50(0.32-0.79)^{* *}$ \\
\hline \multicolumn{4}{|l|}{ Sex } \\
\hline Female versus male & $1.04(0.75-1.45)$ & $0.92(0.39-2.21)$ & $1.26(0.80-1.98)$ \\
\hline \multicolumn{4}{|l|}{ Education } \\
\hline$\geq 12$ years versus $<12$ years & $1.07(0.74-1.56)$ & $0.81(0.31-2.09)$ & $0.65(0.38-1.11)$ \\
\hline Number & 1,071 & 885 & 885 \\
\hline
\end{tabular}

Figures in parentheses are 95\% CIs.

${ }^{1}$ Adjusted for all other demographic characteristics in the table. ${ }^{*} \mathrm{p}<0.05 ;{ }^{* *} \mathrm{p}<0.01$.

allow genetic testing than those without (OR 1.86; 95\% CI 1.14-2.48). As an additional comparison, we evaluated the association between family history of $2 \mathrm{com}$ mon conditions not listed in the consent form - asthma and cancer - and the willingness to donate. As shown by table 2 , a family history of cancer or asthma was not associated with the willingness to donate or allow genetic testing. 
Table 3. Family history and relative odds of consent

\begin{tabular}{llll}
\hline Family history & $\begin{array}{l}\text { Donate biological } \\
\text { sample OR }\end{array}$ & $\begin{array}{l}\text { Genetic testing } \\
\text { OR }^{1}\end{array}$ & $\begin{array}{l}\text { Storage for future } \\
\text { research OR }\end{array}$ \\
\hline Cancer & $1.13(0.78-1.63)$ & $2.07(0.70-6.14)$ & $0.85(0.53-1.36)$ \\
Asthma & $1.21(0.83-1.79)$ & $1.59(0.52-4.81)$ & $1.81(1.02-3.22)^{*}$ \\
Heart problems & $1.41(1.02-1.96)^{*}$ & $0.83(0.34-2.05)$ & $1.08(0.68-1.69)$ \\
Dementia & $0.78(0.52-1.15)$ & $0.84(0.30-2.31)$ & $0.97(0.54-1.72)$ \\
Diabetes & $1.82(1.30-2.54)^{* *}$ & $0.96(0.42-2.19)$ & $1.16(0.75-1.80)$ \\
Depression & $1.73(1.07-2.82)^{*}$ & $0.59(0.23-1.53)$ & $0.85(0.50-1.46)$ \\
Any of the last 4 listed above & $1.68(1.14-2.48)^{* *}$ & $0.80(0.23-2.75)$ & $1.45(0.84-2.50)$ \\
Number & 1,071 & 885 & 885 \\
\hline
\end{tabular}

Figures in parentheses are 95\% CIs. Cancer includes breast, prostate and/or colon cancer; heart problems include stroke, heart surgery before age 60, arteriosclerosis and/or heart disease; dementia includes Alzheimer disease and/or severe memory loss with age. $\mathrm{n}=875$ for family history of asthma due to missing data.

${ }^{1}$ Adjusted for age, sex, race and education. ${ }^{*} \mathrm{p}<0.05 ;{ }^{* *} \mathrm{p}<0.01$.

Table 4. Participant health characteristics and relative odds of consent

\begin{tabular}{llll}
\hline Participant health status & $\begin{array}{l}\text { Donate biological } \\
\text { sample OR }\end{array}$ & $\begin{array}{l}\text { Genetic testing } \\
\text { OR }^{1}\end{array}$ & $\begin{array}{l}\text { Storage for future } \\
\text { research OR }\end{array}$ \\
\hline Cancer & $0.76(0.44-1.32)$ & $0.21(0.08-0.54)^{*}$ & $0.68(0.33-1.40)$ \\
Asthma & $1.27(0.75-2.14)$ & $0.70(0.23-2.13)$ & $1.96(0.87-4.42)$ \\
Heart problems & $1.19(0.75-1.89)$ & $1.93(0.55-6.83)$ & $0.94(0.53-1.67)$ \\
Diabetes & $1.37(0.87-2.16)$ & $0.97(0.35-2.67)$ & $0.97(0.56-1.66)$ \\
Major depressive disorder & $0.86(0.50-1.47)$ & - & $0.91(0.41-2.00)$ \\
Number & 1,071 & 885 & 885 \\
\hline
\end{tabular}

Figures in parentheses are 95\% CIs. Cancer includes self-report of any type; heart problems include selfreport of myocardial infarction, angina, congestive heart failure and/or heart disease.

Cancer: donate biological sample $(n=1,062)$ and testing/storage for future research $(n=880)$ due to missing data. Asthma: donate biological sample $(n=1,059)$ and testing/storage for future research $(n=878)$ due to missing data. Heart problems: donate biological sample $(n=1,059)$ and testing/storage for future research $(n=877)$ due to missing data. Diabetes: donate biological sample $(\mathrm{n}=1,066)$ and testing/storage for future research $(\mathrm{n}=$ $884)$ due to missing data. Major depressive disorder: donate biological sample $(n=1,050)$ and storage for future research $(n=869)$ due to missing data. Small cells prevented statistical adjustment of the regression model of major depressive disorder on genetic testing.

${ }^{1}$ Adjusted for age, sex, race and education. ${ }^{*} \mathrm{p}<0.01$.

\section{Participants' Physical and Mental Health}

Characteristics

Participants with a personal history of cancer were less willing to allow genetic testing after adjusting for age, race, sex and education (OR 0.21; 95\% CI 0.08-0.54) (table 4). Participants with a personal history of major depressive disorder were more likely to allow genetic testing of their DNA sample, but small cells prevented statistical modeling of this relationship (data not show). There were no significant associations between the other physical health conditions and the willingness to donate, allow genetic testing or allow storage for future research.

\section{Discussion}

The consent forms used in the 2004/5 Baltimore ECA Follow-Up Study for the collection of blood and buccal samples modeled the suggested format developed by eth- 
icists and researchers to better inform participants of their alternatives to participation and the risks associated with the donation of a DNA specimen $[1,28]$.

Factors that affect the willingness to donate a biological sample in an epidemiologic study are not the same as those associated with the willingness to allow genetic testing of that sample or storage of the sample for unspecified future research. Age was consistently inversely associated with the willingness to allow genetic testing of the sample, but this effect was modest. Race was the strongest predictor of consenting to storage of the biological sample for future research, with Blacks being $50 \%$ less likely to consent to storage of their samples as compared with members of other racial groups. There was no effect of sex on the willingness to donate, allow testing or allow storage of the sample.

Our results are consistent with previous studies of public attitudes reflected in surveys of hypothetical situations towards donating DNA for unspecified future research. Wang et al. [7] found that approximately one fifth of adults in the United States would be unwilling to consent to donate a DNA sample for either specified genetic testing or storage for future research, a finding that has been reported in European samples as well [5].

Family history of health conditions, particularly those mentioned explicitly in the consent form as compared with those not mentioned (e.g., asthma and cancer), influenced the willingness to donate a biological sample. This finding indicates that researchers may want to include statements regarding the specific research interests (e.g., physiologic processes or pathways) of the study in the consent form rather than blanket statements regarding 'medical research' in order to both better inform participants of the research goals and potentially increase participation.

Our study supports previous findings that individuals are willing to donate biological samples for genetic research without additional compensation or the possibility of personal benefit (e.g., without the possibility of learning test results) from the genetic research [8]. It is possible that long-term contact with the study cohort influenced participation in the biological collection portion of the wave 4 survey, although given that our overall participation rates are similar to those that have been reported by cross-sectional surveys [8], this is unlikely. Our study indicates that race is not associated with the willingness to consent to donate a DNA sample if multiple collection methods are offered, and that investigators should consider offering multiple methods of DNA donation in order to ensure high participation in all groups. We did not find an association between sex and the willingness to donate, which contradicts earlier reports [8].

Those with a positive family history of depression, diabetes, cardiovascular disease or dementia were more likely to donate a biological sample in this study, which indicates that selection bias may threaten the internal validity of future genetic association studies [13]. However, since there was no association between family history and consent to genetic testing of the donated samples, this potential threat to validity should not affect analyses of the 4 genes specified in the consent form.

The relationship of race and the willingness to donate a DNA sample is more nuanced than previously reported. Blacks were not less likely to donate a DNA sample once allowance was made for different methods of collection or for genetic testing than members of other racial groups, but were $50 \%$ less likely to consent to storage of their DNA for future research. This finding is consistent with previous reports of lower participation rates of Blacks in research studies $[7,8,11,29]$. It indicates that confounding by population stratification is a potential threat to the validity of genetic association findings, particularly among the stored samples. Population markers have been genotyped on the samples and will be used to quantify and adjust for population stratification in future analyses.

Participants who refuse to consent to donate a biological specimen for genetic analysis are not questioned as to the reasons for their refusal, and therefore, we can only speculate as to why certain groups were less likely to participate in this aspect of the survey. Researchers are beginning to study the participant characteristics and attitudes associated with the willingness to donate biological samples for research $[6,7,30-32]$ and towards research on stored samples [33-35], but special attention needs to be paid to the concerns of minorities. Research is needed to determine what concerns participants, particularly Black Americans, have about the storage of DNA and how those concerns can be addressed, as well as how media portrayals [36], issues related to social inequality [37] and privacy concerns [38] affect public attitudes about genetic research. Research using focus groups, rather than broad questionnaire-driven epidemiologic research, is a promising approach to understanding these concerns [39]. Consent for the storage of samples for unspecified research involves complex respondent burdens (e.g., research can be done on the samples after the participant is deceased, genetic research may reveal liabilities that have been passed on to participant descendants) and thus requires consideration by researchers and those obtaining 
consent from participants $[5,7,21,40-43]$. There is a large body of research concerning the tendency for Black Americans to be underrepresented in some types of research $[11,29,30,44]$, and the findings from this research may be used to inform study design and execution to ensure adequate participation of racial minorities.

\section{Acknowledgement}

Supported by National Institute of Mental Health grants (R0147447 and T32-14592).

\section{References}

1 Beskow L, Burke W, Merz J, Barr P, Terry S, Penchaszadeh V, Gostin L, Gwinn M, Knoury $\mathrm{M}$ : Informed consent for population-based research involving genetics. JAMA 2001; 286:2315-2321.

-2 Durfy S, Bowen D, McTiernan A, Sporleder $\mathrm{J}$, Burke W: Attitudes and interest in genetic testing for breast and ovarian cancer susceptibility in diverse groups of women in western Washington. Cancer Epidemiol Biomarkers Prev 1999;8:369-375.

$\checkmark 3$ Helmes A, Bowen D, Bowden R, Bengel J: Predictors of participation in genetic research in a primary care physician network. Cancer Epidemiol Biomarkers Prev 2000;9 1377-1379.

4 Kettis-Lindblad A, Ring L, Viberth E, Hansson $\mathrm{M}$ : Genetic research and donation of tissue samples in biobanks. What do potential sample donors in the Swedish general population think? Eur J Public Health 2005;4: 443-440.

$>5$ Hoeyer K, Olofsson B, Mjorndal T, Lynoes N: Informed consent and biobanks: a population-based study of attitudes towards tissue donation for genetic research. Scand J Public Health 2004;32:224-229.

6 Wong M, Chia K, Yam W, Teodoro G, Lau K: Willingness to donate blood samples for genetic research: a survey from a community in Singapore. Clin Genet 2004;64:45-51.

$>7$ Wang S, Fridinger F, Sheedy K, Khoury M: Public attitudes regarding the donation and storage of blood specimens for genetic research. Community Genet 2001;4:18-26.

-8 McQuillan G, Pan Q, Porter K: Consent for genetic research in a general population: an update on the National Health and Nutrition Examination Survey experience. Genet Med 2006;8:354-360.

9 Bauer J, Rezaishiraz H, Head K, Cowell J, Belper G, Aiken M, Cummings M, Hyland A: Obtaining DNA from a geographically dispersed cohort of current and former smokers: use of mail-based mouthwash collection and monetary incentives. Nicotine Tob Res 2004;6:439-446.

$\checkmark 10$ Seybolt L, Vachon C, Potter K, Kheng W, Kushi L, McGovern P, Sellers T: Evaluation of potential sources of bias in a genetic epidemiologic study of breast cancer. Genet Epidemiol 1997;14:85-95.
11 Mancuso C, Glendon G, Anson-Cartwright L, Shi E, Andrulis I, Knight J: Ethnicity, but not cancer family history, is related to response to a population-based mailed questionnaire. Ann Epidemiol 2004;14:36-43.

12 Criqui M: Response bias and risk rations in epidemiologic studies. Am J Epidemiol 1979; 109:394-399.

13 Bergstrand R, Vendin A, Wilhelmsson C, Wilhelmsen L: Bias due to non-participation and heterogeneous sub-groups in population surveys. J Chronic Dis 1983;36:725728.

14 Greenland S: Response and follow-up bias in cohort studies. Am J Epidemiol 1977;106: 184-187.

15 Thomas D: Statistical Methods in Genetic Epidemiology. New York, Oxford University Press, 2004.

16 Race, Ethnicity and Genetics Working Group: The use of racial, ethnic and ancestral categories in human genetics research. Am J Hum Genet 2005;77:519-532.

17 Steinberg K, Beck J, Nickerson D, GarciaClosas M, Gallagher M, Caggana M, Reid Y, Costentino M, Ji J, Johnson D, Hayes R, Earley M, Lorey F, Hannon H, Knoury M, Sampson E: DNA banking for epidemiologic studies: a review of current practices. Epidemiology 2002;13:246-254.

-18 Le Marchand L, Lum-Jones A, Saltzman B, Visaya V, Nomura A, Kolonel L: Feasibility of collecting buccal cell DNA by mail in a cohort study. Cancer Epidemiol Biomarkers Prev 2001;10:701-703.

19 Lum A, Le Marchand L: A simple mouthwash method for obtaining genomic DNA in molecular epidemiological studies. Cancer Epidemiol Biomarkers Prev 1998;7:719-724.

20 Williams G, Schroeder D: Human genetic banking: altruism, benefit and consent. New Genet Soc 2004;23:89-103.

21 Matsui K, Kita Y, Ueshima H: Informed consent, participation in, and withdrawal from a population based cohort study involving genetic analysis. J Med Ethics 2005;31:385392.

22 Regier D, Myers J, Kramer M, Robbins L, Blazer D, Hough R, Eaton W, Locke B: The NIMH Epidemiologic Catchment Area program: historical context, major objectives, and study population characteristics. Arch Gen Psychiatry 1984;41:934-941.
23 Robins L, Helzer J, Croughan J, Ratcliff K: National Institute of Mental Health Diagnostic Interview Schedule: its history, characteristics, and validity. Arch Gen Psychiatry 1981;38:381-389.

24 Eaton W, Neufeld K, Chen L-C, Cai G: A comparison of self-report and clinical diagnostic interviews for depression. Arch Gen Psychiatry 2000;57:217-222.

25 Okura Y, Urban L, Mahoney D, Jacobsen S, Rodeheffer R: Agreement between self-report questionnaires and medical record data for diabetes, hypertensions, myocardial infarction and stroke but not for heart failure. J Clin Epidemiol 2004;57:1096-1103.

26 Zhu K, McKnight B, Stergachis A, Daling J, Levine R: Comparison of self-report data and medical records data: results from a case-control study on prostate cancer. Int J Epidemiol 1999;28:409-417.

27 STATA Statistical Software. College Station, Stata Corportation, 2004.

28 Annas G: Reforming informed consent to genetic research. JAMA 2001;286:23262328.

29 Corbie-Smith G, Thomas S, Williams M, Moody-Ayer S: Attitudes and beliefs of African Americans toward participation in medical research. J Gen Intern Med 1999;14:537546.

30 Green B, Partridge E, Fouad M, Hohler C, Crayton E, Alexander L: African American attitudes regarding cancer clinical trials and research studies: results from focus group methodology. Ethn Dis 2000;10:76-86.

31 Schwartz M, Rothenberg K, Joseph LBJ, Lerman C: Consent to the use of stored DNA for genetics research: a survey of attitudes in the Jewish population. Am J Med Genet 2001;98: 336-342.

32 Wong M, Chia K, Wee S, Chia S, Lee J, Koh W, Shen H, Thumboo J, Sofjan D: Concerns over participation in genetic research among Malay-Muslins, Chinese, and Indians in Singapore: a focus group study. Community Genet 2004;7:44-54

33 Wendler D, Emanuel E: The debate over research on stored biological samples: what do sources think? Arch Intern Med 2002;162: 1457-1462. 
-34 Chen D, Rosenstein D, Muthappan P, et al: Research with stored biological samples: what do research participants want? Arch Intern Med 2005;165:652-655.

>35 Pentz R, Billot L, Wendler D: Research on stored biological samples: views of African American and White American cancer patients. Am J Med Genet 2006;140A:733-739.

\$6 Geller G, Bernhardt B, Holtzman N: The media and public reaction to genetic research. JAMA 2002;287:773.

$>37$ Schultz A, Caldwell C, Foster S: 'What are they going to do with the information?' Latino/Latina and African American perspectives on the Human Genome Project. Health Educ Behav 2003;30:151-169.
38 Fuller B, Kahn M, Barr P, Biesecker L, Crowley E, Garber J, Mansoura M, Murphy P, Murray J, Phillips J, Rothenberg K, Rothstein M, Stopfer J, Swergold G, Weber B, Collins F, Hudson K: Privacy in genetics research. Science 1999;285:1359-1361.

39 Bates B, Lynch J, Bevan J, Condit C: Warranted concerns, warranted outlooks: a focus group study of public understandings of genetic research. Soc Sci Med 2005;60:331344.

40 Clayton E, Steinberg K, Khoury M, Thomson E, Andrews L, Kahn M: Informed consent for genetic research on stored tissue samples. JAMA 1995;275:1786-1792.

41 Hoeyer K, Olofsson B, Mjorndal T, Lynoe N: The ethics of research using biobanks: reason to question the importance attributed to informed consent. Arch Intern Med 2005; 165:97-100.
42 Meslin E, Quaid K: Ethical issues in the collection, storage, and research use of human biological materials. J Lab Clin Med 2004; 144:229-234.

43 Trauth J, Musa D, Siminoff L, Jewell I, Ricci E: Public attitudes regarding willingness to participate in medical research studies. J Health Soc Policy 2000;12:23-43.

44 Shavers-Hornaday V, Lynch C, Burmeister L, Torner J: Why are African Americans under-represented in medical research studies? Impediments to participation. Ethn Health 1997;2:31-45. 